\title{
Efeito do mel e do soro autólogo na cicatrização do epitélio corneano em coelhos
}

\author{
Effect of honey and autologous serum on corneal epithelial healing in rabbits
}

\author{
Gustavo Ricci Malavazzi ${ }^{1}$ \\ Jonathan Clive Lake ${ }^{2}$ \\ Paulo Elias Correa Dantas ${ }^{3}$
}

Trabalho realizado no Departamento de Oftalmologia da Irmandade Santa Casa de Misericórdia de São Paulo.

${ }^{1}$ Orientador do Instituto da Catarata da Universidade Federal de São Paulo (UNIFESP). São Paulo (SP).

${ }^{2}$ Assistente da Seção de Córnea e Doenças Externas do Departamento de Oftalmologia da Irmandade da Santa Casa de Misericórdia de São Paulo. São Paulo (SP).

${ }^{3}$ Assistente da Seção de Córnea e Doenças Externas do Departamento de Oftalmologia da Irmandade da Santa Casa de Misericórdia de São Paulo. São paulo (SP).

Endereço para correspondência: Gustavo Ricci Malavazzi - Rua Guarará 364, apto 82 - São Paulo (SP) CEP 01425-000

E-mail: g.malavazzi@uol.com.br

Recebido para publicação em 18.02.2004

Versão revisada recebida em 24.02.2005

Aprovação em 04.03.2005

Nota Editorial: Após concluída a análise do artigo sob sigilo editorial e com a anuência da Dra. Silvana Artioli Schellini sobre a divulgação de seu nome como revisora dele, agradecemos sua participação neste processo.

\begin{tabular}{|l|}
\hline RESUMO \\
\hline Objetivo: Avaliar a eficácia de substâncias consideradas estimulantes da \\
cicatrização, como o mel puro e o soro autólogo a $20 \%$ na cicatrização do \\
epitélio corneal de coelhos. Métodos: Foi realizada a remoção do epitélio \\
corneal de dois grupos de coelhos que receberam a instilação de solução \\
de mel puro (G1) ou soro autólogo(G2) a cada 4horas. O olho contralateral \\
foi usado como controle e submetido ao mesmo procedimento de remoção \\
do epitélio, recebendo a instilação de BSS ${ }^{\circledR}$. A área de desepitelização \\
corneal foi avaliada 12, 24 e 48 horas após a indução do defeito epitelial. \\
Resultados: Os grupos estudados foram estatisticamente semelhantes: \\
mel (48 horas) e controle (48 horas) p<0,87; soro autólogo (48 horas) e \\
controle (48 horas) p<0,072. Conclusão: Mesmo constatando-se discreta \\
melhora clínica no uso tópico do soro autólogo, a cicatrização do epitélio \\
corneal não foi significativamente diferente durante este estudo em ne- \\
nhum dos grupos estudados. \\
\hline
\end{tabular}

Descritores: Epitélio da córnea/patologia; Cicatrização de feridas; Doenças da córnea/ terapia; Infecção dos ferimentos/terapia; Mel/uso terapêutico; Soluções oftálmicas/uso terapêutico; Coelhos

\section{INTRODUÇ̃̃̃O}

Os defeitos epiteliais da córnea continuam sendo preocupação na clínica oftalmológica diária. Condições que interferem no processo de cicatrização, como doenças ou traumas (mecânicos, químicos ou térmicos), podem alterar a integridade do epitélio e suas funções. O tratamento inclui instilação de lágrimas artificiais sem preservantes ${ }^{(1)}$; oclusão de um ou dos dois pontos lacrimais; óculos de proteção; tarsorrafia provisória; transplante de limbo (nos casos de deficiência das células germinativas do limbo) ${ }^{(2)}$; lente de contato terapêutica; membrana amniótica ${ }^{(3)}$ ou associação de duas ou mais dessas opções.

A aplicação do mel como forma de tratamento de algumas doenças, em seres humanos, é conhecida desde a medicina antiga. Seu uso tópico como antibacteriano e cicatrizante no tratamento de feridas ${ }^{(4)}$, queimaduras e lesões ulceradas da pele ${ }^{(5)}$, já foi demonstrado. O mel também atua como barreira viscosa, que impede a entrada de substâncias e a perda de fluidos para o meio externo ${ }^{(5)}$. A atividade antibacteriana do mel ocorre devido a seu alto valor de gradiente osmolar, que o faz agir, tanto como bactericida, quanto como bacteriostático(6). Além disso, apresenta alguns compostos que auxiliam no mecanismo bioquímico da cicatrização, produzidos pela atividade enzimática, como por exemplo o peróxido de hidrogênio e derivados naturais das plantas, de onde é extraído. Na experiência do Departamento de Cirurgia da Faculdade de Ciências Médicas da Santa Casa de 
Misericórdia São Paulo, o uso do mel como tratamento de lesões de pele se demonstrou eficaz e uma alternativa de baixo custo financeiro.

Foi demonstrado que substâncias presentes na lágrima humana normal e no soro humano, como fator de crescimento epidérmico (EGF), vitamina A, acetil-colina e a substância P, são importantes coadjuvantes na cicatrização e renovação das células epiteliais, principalmente nos casos de defeito epitelial persistente ${ }^{(7)}$.

Com base na importância da cicatrização do epitélio da córnea e na possibilidade da ação e eficácia dessas soluções no olho, este estudo objetiva avaliar a atividade do mel e do soro autógeno a $20 \%$ sobre defeito epitelial da córnea, produzido experimentalmente, em olhos de coelhos.

\section{MÉTODOS}

Foram selecionados 20 coelhos albinos da raça Nova Zelândia, sadios, com peso variando entre $2.000 \mathrm{~g}$ e $3.000 \mathrm{~g}$, provenientes do Biotério da Faculdade de Ciências Médicas da Santa Casa de São Paulo. Os animais foram examinados pela médica veterinária responsável e mantidos na Unidade de Técnica Cirúrgica e Cirurgia Experimental (UTECE/Santa Casa) durante toda a pesquisa. $\mathrm{O}$ manuseio dos animais de experimentação seguiu as normas e orientações do Comitê Brasileiro de Estudos em Animais de Experimentação (COBEA), da Association for Research in Vision and Ophthalmology (ARVO) e da UTECE/ Santa Casa. Foram excluídos os coelhos com doença prévia ou vigente. Após identificação aleatória dos animais, numerandosos de 1 a 10, na face interna da orelha, com caneta hidrográfica, os coelhos foram separados em dois grupos (G1 e G2).

Metodologia empregada na criação do defeito epitelial (G1 e G2) - Os animais foram anestesiados com injeção intramuscular de $0,4 \mathrm{mg}$ de cloridrato de tiletamina e cloridrato de zolazepam (Zoletil ${ }^{\circledR}$, Virbac) e $0,3 \mathrm{mg}$ de citrato de fentanila e droperidol (Inoval ${ }^{\circledast}$, Jansen) por quilo de peso. Foi aplicado colírio de cloridrato de tetracaína (Colírio Anestésico ${ }^{\circledR}$, Allergan) em ambos os olhos e a seguir, realizada a anti-sepsia da região palpebral com polivinil pirrolidona iodado (PVPI). Colocado o blefarostato de Barraquer, adaptado para cirurgia experimental, removeu-se manualmente uma área de $13 \mathrm{~mm}$ de diâmetro do epitélio corneal com lâmina descartável no 15 , com o cuidado de não se lesar a membrana basal.

Procedimento empregado para a obtenção do soro autólogo (G2) - Após a tricotomia das orelhas do animal, foi retirado $5 \mathrm{ml}$ de sangue venoso com gelco descartável G22. Imediatamente o sangue foi centrifugado a 1.500 rotações por minuto, durante 1 hora. Após este período, foi retirado $1 \mathrm{ml}$ de soro do tubo e adicionado a $4 \mathrm{ml}$ de solução salina balanceada, obtendo-se assim colírio com soro autólogo de cada animal, na concentração de $20 \%$. O colírio ficou armazenado em geladeira, disponível no laboratório, durante todo o estudo.

Procedimento para avaliação do defeito epitelial - $O$ defeito epitelial foi corado com colírio de Fluoresceína 2\% (Aller-
$\operatorname{gan}^{\circledR}$ ) e medido com compasso cirúrgico nos eixos de $90^{\circ} \mathrm{e}$ $180^{\circ}$ em relação à fenda palpebral, em ambos os olhos. Foi tomada a maior medida de cada um dos eixos e realizada a média aritmética desses valores.

Modo de aplicação do tratamento - Os animais do Grupo 1 receberam uma gota de mel (Superbom ${ }^{\circledast}$, IAE, Brasil) no fundo de saco conjuntival de um dos olhos. No olho contralateral foi instilado uma gota de solução salina balanceada $\left(\mathrm{BSS}^{\circledR}\right.$, $\mathrm{Al}-$ con). A aplicação foi feita imediatamente após a remoção do epitélio e então, a cada quatro horas. Os animais do Grupo 2 receberam uma gota da solução de soro autólogo a $20 \%$ no fundo de saco conjuntival de um dos olhos. No olho contralateral foi instilado uma gota de solução salina balanceada. A aplicação iniciou-se imediatamente após o preparo do colírio com soro autólogo, e a cada quatro horas.

Os animais foram examinados após anestesia tópica e o defeito epitelial foi medido com compasso cirúrgico milimetrado, logo após aplicação do corante de fluoresceína, sob luz de cobalto, numa periodicidade de 12, 24 e 48 horas. Os dados clínicos foram colhidos a partir de observador independente, mascarado, que preencheu formulário de dados entregue pelo pesquisador. O pesquisador recebeu compasso cirúrgico para avaliar a maior medida dos eixos de $90^{\circ}$ e $180^{\circ}$, parâmetro de avaliação da área desepitelizada.

Após 48 horas, os animais foram sacrificados com injeção de $40 \mathrm{mg} / \mathrm{kg}$ de tiopentato sódico (Thionenbutal ${ }^{\circledR}$, Tiopental Sódico, $\mathrm{Abbott}^{\circledR}$ ) e $0,5 \mathrm{ml}$ de cloreto de potássio, segundo as normas de eutanásia de animais de experimentação propostos pela UTECE/Santa Casa.

A análise estatística das medidas do defeito epitelial da córnea foi realizada pelo método de Kruskal-Wallis para a avaliação da significância do estudo. Foi considerado o índice de $95 \%(p \leq 0,05)$ de confiança entre os resultados obtidos.

\section{RESULTADOS}

Os resultados da observação clínica e sua quantificação podem ser analisados nos quadros 1 (A e B) e 2 (A e B).

Avaliação clínica - Todos os olhos do estudo mostraram inflamação um dia após o defeito epitelial caracterizada por hiperemia da conjuntiva. Todos os olhos estudados apresentaram redução da área deseptelizada após 24 horas. A observação ectoscópica da íris e da câmara anterior de todos os olhos estudados foi de difícil observação decorrente da diminuição da transparência da córnea e da presença de secreção em ambos os olhos.

Avaliação das dimensões do defeito epitelial - As medidas referentes às dimensões das úlceras corneais estão apresentadas nos quadros 1 (A e B) e 2 (A e B). No primeiro grupo, quadro 1 (A e B), três coelhos (30\%) tratados com mel apresentaram olhos com cicatrização mais eficiente que o olho controle. Em 4 coelhos $(40 \%)$ o olho controle apresentou cicatrização mais eficiente e em três coelhos (30\%) não foi observada diferença entre os olhos (coelhos: 2 , 4 e 6). Os coelhos identificados com os números 8,9 e 10 , apresentaram 


\begin{tabular}{|c|c|c|c|c|}
\hline \multicolumn{5}{|c|}{$\begin{array}{l}\text { Quadro 1A. Medidas dos olhos dos coelhos do grupo } 1 \text { tratado com } \\
\text { mel }(n=10) \text {. Santa Casa, SP, } 2000\end{array}$} \\
\hline & 00horas & 12 horas & 24 horas & 48 horas \\
\hline Coelho 1 & 13,0 & 11,0 & 10,0 & 5,5 \\
\hline Coelho 2 & 13,0 & 9,5 & 9,5 & 6,0 \\
\hline Coelho 3 & 13,0 & 7,5 & 7,5 & 4,0 \\
\hline Coelho 4 & 13,0 & 11,5 & 10,0 & 7,0 \\
\hline Coelho 5 & 13,0 & 11,5 & 10,5 & 6,5 \\
\hline Coelho 6 & 13,0 & 12,0 & 10,5 & 7,5 \\
\hline Coelho 7 & 13,0 & 10,5 & 10,5 & 7,5 \\
\hline Coelho 8 & 13,0 & 11,0 & 10,5 & 9,5 \\
\hline Coelho 9 & 13,0 & 11,5 & 11,5 & 9,5 \\
\hline Coelho 10 & 13,0 & 12,0 & 11,5 & 11,0 \\
\hline
\end{tabular}

\begin{tabular}{|c|c|c|c|c|}
\hline \multicolumn{5}{|c|}{$\begin{array}{l}\text { Quadro 1B. Medidas dos olhos contralaterais dos coelhos do grupo } \\
\left.1 \text { tratado com solução controle (BSS }{ }^{\circledast}\right)(n=10) \text {. Santa Casa, SP, } 2000\end{array}$} \\
\hline & 00horas & 12 horas & 24 horas & 48 horas \\
\hline Coelho 1 & 13,0 & 12,0 & 12,0 & 7,5 \\
\hline Coelho 2 & 13,0 & 10,0 & 10,0 & 6,0 \\
\hline Coelho 3 & 13,0 & 10,0 & 8,5 & 6,0 \\
\hline Coelho 4 & 13,0 & 11,5 & 10,0 & 7,0 \\
\hline Coelho 5 & 13,0 & 11,5 & 11,0 & 7,0 \\
\hline Coelho 6 & 13,0 & 11,5 & 10,0 & 7,5 \\
\hline Coelho 7 & 13,0 & 11,0 & 10,0 & 5,5 \\
\hline Coelho 8 & 13,0 & 11,5 & 11,5 & 8,5 \\
\hline Coelho 9 & 13,0 & 12,0 & 11,5 & 9,0 \\
\hline Coelho 10 & 13,0 & 12,0 & 11,5 & 9,5 \\
\hline
\end{tabular}

cicatrização mais lenta em relação aos demais animais do grupo, embora continuassem saudáveis e com alimentação semelhante à do grupo.

A média das medidas dos defeitos epiteliais nos olhos que receberam mel como tratamento (medida após 48 horas do

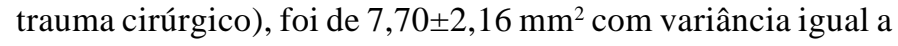
$4,67 \mathrm{~mm}^{2}$. Nos olhos contralaterais, que receberam solução salina balanceada como controle (medida após 48 horas do

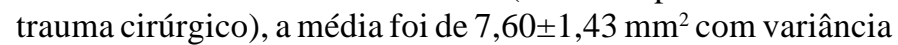
igual a 2,04 $\mathrm{mm}^{2}$. A análise estatística entre as duas amostras do grupo 1, estudados após 48 horas, demonstrou $\mathrm{p}=0,877$.

No grupo 2, quadros 2(A e B), sete coelhos (70\%) tratados com soro autólogo apresentaram olhos com cicatrização mais eficiente que o olho controle (solução salina balanceada) e três coelhos (30\%) em que o olho controle apresentou cicatrização mais eficiente.

A média das medidas dos defeitos epiteliais nos olhos do grupo 2, que receberam soro autólogo como tratamento (medi-

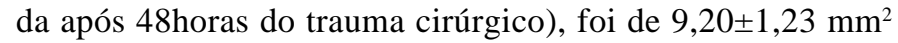
com variância igual a $1,51 \mathrm{~mm}^{2}$. Porém nos olhos contralaterais, que receberam solução salina balanceada como controle (medida após 48horas do trauma cirúrgico), a média foi de 10,2

\begin{tabular}{|c|c|c|c|c|}
\hline \multicolumn{5}{|c|}{$\begin{array}{l}\text { Quadro 2A. Medidas dos olhos dos coelhos do grupo } 2 \text { tratado com } \\
\text { soro autólogo }(n=10) \text {. Santa Casa, SP, } 2000\end{array}$} \\
\hline & 00horas & 12 horas & 24 horas & 48 horas \\
\hline Coelho 1 & 13,0 & 13,0 & 13,0 & 12,0 \\
\hline Coelho 2 & 13,0 & 13,0 & 12,5 & 10,0 \\
\hline Coelho 3 & 13,0 & 13,0 & 12,5 & 9,5 \\
\hline Coelho 4 & 13,0 & 13,0 & 12,5 & 10,5 \\
\hline Coelho 5 & 13,0 & 13,0 & 12,5 & 9,0 \\
\hline Coelho 6 & 13,0 & 13,0 & 12,0 & 7,5 \\
\hline Coelho 7 & 13,0 & 13,0 & 12,5 & 8,0 \\
\hline Coelho 8 & 13,0 & 13,0 & 12,5 & 7,5 \\
\hline Coelho 9 & 13,0 & 13,0 & 13,0 & 10,5 \\
\hline Coelho 10 & 13,0 & 13,0 & 12,5 & 10,0 \\
\hline
\end{tabular}

\begin{tabular}{|c|c|c|c|c|}
\hline \multicolumn{5}{|c|}{$\begin{array}{l}\text { Quadro 2B. Medidas dos olhos contralaterais dos coelhos do grupc } \\
2 \text { tratado com solução controle }\left(\text { BSS }^{\circledR}\right)(n=10) \text {. Santa Casa, SP, } 2000\end{array}$} \\
\hline & 00horas & 12 horas & 24 horas & 48 horas \\
\hline Coelho 1 & 13,0 & 13,0 & 12,5 & 10,5 \\
\hline Coelho 2 & 13,0 & 13,0 & 13,0 & 9,5 \\
\hline Coelho 3 & 13,0 & 13,0 & 12,5 & 11,0 \\
\hline Coelho 4 & 13,0 & 13,0 & 12,5 & 9,5 \\
\hline Coelho 5 & 13,0 & 13,0 & 13,0 & 10,0 \\
\hline Coelho 6 & 13,0 & 13,0 & 12,5 & 9,0 \\
\hline Coelho 7 & 13,0 & 13,0 & 13,0 & 9,0 \\
\hline Coelho 8 & 13,0 & 13,0 & 13,0 & 10,0 \\
\hline Coelho 9 & 13,0 & 13,0 & 13,0 & 11,5 \\
\hline Coelho 10 & 13,0 & 13,0 & 13,0 & 11,0 \\
\hline \multicolumn{5}{|c|}{$\begin{array}{l}\text { *Quantificação do defeito epitelial em mm (média da maior medida corneal nos } \\
\text { eixos } 180^{\circ} \text { e } 90^{\circ} \text { ) }\end{array}$} \\
\hline
\end{tabular}

$\pm 0,92 \mathrm{~mm}^{2}$ com variância igual a $0,84 \mathrm{~mm}^{2}$. A análise estatística entre as duas amostras do grupo 2, estudados após 48horas, demonstrou $\mathrm{p}=0,072$.

\section{DISCUSSÃO}

O coelho foi o animal escolhido para o presente estudo por ter os olhos de tamanho adequado para o experimento. A escolha também se deu por se tratar de animais resistentes à manipulação durante o estudo e pela facilidade de obtenção de animais saudáveis no biotério. Não foi feita restrição ao sexo dos animais pois o período de pesquisa foi de 48 horas não havendo riscos de influência da variação hormonal, que podem estar presentes nas fêmeas. A retirada do epitélio foi feita em um diâmetro médio de $13 \mathrm{~mm}$ para evitar irregularidade das bordas do defeito epitelial. O epitélio de ambos os olhos foi removido por haver necessidade de se ter o do olho contralateral como controle, apesar de se ter o prejuízo da redução visual bilateral.

A opção pelo mel como forma de tratamento de desepitelização corneal se deve à sua recente re-introdução no tratamento 
de feridas de pele infectadas, estéreis ou em necrose ${ }^{(8-9)}$. Inicialmente aventou-se a hipótese de se estudar diferentes diluições do mel, com o intuito de verificar qual a mais eficaz. Porém, é descrito que o mel puro é mais eficiente do que em outras concentrações ${ }^{(10)}$, o que nos fez optar pelo mel puro, disponível comercialmente. $\mathrm{O}$ pH de 3,6 e a hipertonicidade (alta pressão osmolar) são os principais responsáveis pelo papel bactericida e bacteriostático do mel ${ }^{(6)}$. Composto por aproximadamente $40 \%$ de frutose, $20 \%$ de água, o mel também contém aminoácidos, vitaminas (ácido nicotínico, piridoxina e tiamina), enzimas (diastase, invertase, peróxido de hidrogênio, catalase e glicose oxidase) e minerais (potássio, ferro, magnésio, fósforo, cobre e cálcio ${ }^{(8-9)}$. Assim, pode-se considerar o mel como excelente fonte de nutrientes para a área desepitelizada, local em processo de catabolismo. Acredita-se também que o peróxido de hidrogênio e o ácido fenólico tenham influência direta no processo e na velocidade da cicatrização ${ }^{(11)}$.

Optou-se pelo mel industrializado (pasteurizado) porque a existência de microorganismos como o Clostridium botuli$n_{u m^{(12)}}$ na forma de esporos, poderia invalidar os resultados. Vale ressaltar que a pasteurização, embora mais acessível, não é considerada como o melhor método de eliminar esses microorganismos, pois os compostos do mel que são termolábeis, principalmente os de origem protéica, sofrem desnaturação ${ }^{(6)}$.

No presente estudo, após 48 horas, a área desepitelizada residual dos olhos do Grupo 1, nos quais aplicou-se mel, não foi significativamente menor que a área residual dos olhos nos quais foi instilada a solução controle $(\mathrm{p}<0,87)$. Uma série de variáveis, como tempo de tratamento, tipo de animal, tipo de mel, pasteurização do mel e freqüência do tratamento (posologia), podem ter contribuído para esta observação.

No Grupo 2, na medida das 48 horas, a área residual dos olhos tratados com o soro autólogo não foi significativamente menor do que a área dos olhos controle $\left(\mathrm{BSS}^{\circledR}\right)$. Entretanto, sete dos dez coelhos apresentaram melhor cicatrização quando tratados com soro autólogo apesar de não haver diferença estatística significativa, os resultados sugerem possível melhora da cicatrização corneal com o uso do soro autólogo.

A escolha do soro autólogo e sua concentração teve como referência os estudos em que é estabelecida a importância de substâncias presentes no soro autólogo como a vitamina $\mathrm{A}$, o hormônio EGF (fator de crescimento epidermal) e o TGF- $\beta$ (fator de crescimento transformador- $\beta$ ) no processo de cicatrização corneal. A vitamina A atuaria como nutriente das fibras nervosas da córnea e o EGF como estimulante das células do epitélio corneal $^{(1)}$, levando o soro autólogo ao sucesso na cicatrização dos defeitos epiteliais corneais persistentes de até $63 \%$ com cerca de um mês de tratamento em seres humanos ${ }^{(1)}$.

Os valores dos olhos em que se utilizou a solução controle $\left(\mathrm{BSS}^{\oplus}\right)$, foram significativamente diferentes nos grupos 1 e 2 . Isto sugere que os animais dos grupos 1 e 2 possam ter respostas assimétricas quanto à velocidade de cicatrização do epitélio. Assim, a comparação entre as substâncias, mel e soro autólogo não deve ser feita no presente estudo, uma vez que há indícios de que os grupos são diferentes. Essas variações dos grupos podem ter sido influenciadas por variáveis de difícil controle: os dois grupos não foram simultâneos no laboratório havendo diferença entre os grupos de uma semana e a Unidade de Técnica Cirúrgica e Cirurgia Experimental (UTECE/Santa Casa) não dispõe de climatização do biotério. Estas variáveis poderiam explicar as diferenças observadas entre os grupos.

Apoiados nos resultados desta pesquisa, o mel de abelha não difere do BSS na cicatrização dos defeitos epiteliais da córnea. Nos futuros estudos que envolvam o mel, sugerimos que sejam ajustados vários parâmetros que foram duvidosos neste primeiro estudo como a concentração, a posologia e possíveis associações com outras drogas.

Baseados nos resultados da presente pesquisa, o Soro Autólogo, não difere do BSS na cicatrização dos defeitos epiteliais da córnea. Embora haja trabalhos na literatura mundial que demonstraram a eficácia do Soro Autólogo sobre a epitelização da córnea, sugerimos que outros estudos sejam desenvolvidos a fim de que novas comparações e resultados possam ser observados.

\section{ABSTRACT}

Purpose: To evaluate the efficacy of pure honey and $20 \%$ autologous serum and $\mathrm{BSS}^{\circledR}$ in corneal epithelial healing in rabbits after 48 hours. Methods: All solutions were applied after an epithelial removal of 13-millimeters diameter area. Areas of epithelial healing were studied at 12, 24 and 48 hours. The eyes were treated every four hours during 2 days. All treated eyes were assigned to a control group (contralateral eye) treated with a balanced saline solution. Results: All studied groups were not significantly differents. In group one, the eyes treated with honey and the control were similar ( $\mathrm{p}<0.87)$. In the second group the eyes treated with autologos serum and the control presented no difference in the mean score $(\mathrm{p}<0.072)$. Conclusion: Corneal epithelial healing in rabbits did not show improvement after application of either honey or autologous serum. It was possible to stabilish that the autologous serum treated eyes were clinicaly better than the control group but without statistical significance.

Keywords: Epithelium, corneal/pathology; Wound healing; Corneal diseases/therapy; Wound infection/therapy; Honey/ therapeutic use; Ophthalmic solutions/therapeutic use; Rabbits

\section{REFERÊNCIAS}

1. Tsubota K, Goto E, Shimmura S, Shimazaki J. Treatment of persistent corneal epithelial defect by autologous serum application. Ophthalmology. 1999; 106(10):1984-9.

2. Tsubota K. New approaches in dry eye management. Supplying missing tear components to the ocular surface epithelium. In: Kinoshita S, Ohashi Y, eds. Current opinions in the Kyoto Cornea Club. Amsterdam: Kugler; 1997. p.27-32.

3. Lee SH, Tseng SC. Amniotic membrane transplantation for persistent epithelial defects with ulceration. Am J Ophthalmol. 1997;123(3):303-12.

4. Bose B. Honey or sugar in treatment of infected wounds? Lancet. 1982;1(8278): 963.

5. Postmes T, Van Den Bogaard AE, Hazen M. Honey for wounds, ulcers, and skin graft preservation. Lancet. 1993;341(8847):756-7. 
6. Jeddar A, Kharsany A, Ramsaroop UG, Bhamjee A, Haffejee IE, Moosa A. The antibacterial action of honey. An in vitro study. S Afr Med J. 1985;67(7):257-8.

7. Tsubota K, Satake Y, Shimazaki J. Treatment of severe dry eye [letter]. Lancet. 1996;348(9020):123

8. Zumla A, Lulat A. Honey: a remedy rediscovered. J R Soc Med. 1989;82(7): 384-5.

9. Wahdan HA. Causes of the antimicrobial activity of honey. Infection. 1998; 26(1):26-31.
10. Efem Se, Udoh KT, Iwara CI. The antimicrobial spectrum of honey and its clinical significance. Infection. 1992;20(4):227-9.

11. Bergman A, Yanai J, Weiss J, Bell D, David MP. Acceleration of wound healing by topical application of honey. An animal model. Am J Surg. 1983; 145(3):374-6.

12. Snowdon JA, Cliver DO. Microorganisms in honey. Int J Food Microbiol. 1996;31(1):1-26. 